\title{
Comparing attitudes and characteristics of organic, former organic and conventional farmers: Evidence from Ireland
}

\author{
Doris Läpple \\ Department of Economics, School of Business and Economics, National University of Ireland, Galway, Ireland. \\ Corresponding author: doris.laepple@nuigalway.ie
}

\begin{abstract}
Despite an overall growth rate of the organic farming sector in the European Union, a considerable number of farmers cease organic production each year. Given the commitment of many European governments to increase the size of their organic farming sectors, reducing the rate of withdrawals from organic production may be an easier option than attracting new farmers into organic farming. In order to reduce the rate of withdrawals, knowledge about those farmers is required. However, to date, little is known about farmers who adopt and subsequently abandon organic farming. This study attempts to fill this gap in the literature by comparing and contrasting the farm and personal characteristics of organic, former organic and conventional farmers. To this end, primary data from 596 Irish cattle and sheep farmers are utilized. Overall, the findings reveal significant differences between the three groups. More specifically, organic farmers are found to be the most environmentally aware farmers, who also rate information gathering as more important than the remaining two groups. Organic farmers are younger, better educated and more likely to be women than conventional farmers. Former organic farmers stand out to be the least risk averse group and also express lower environmental awareness than organic farmers. Conventional farmers are found to be the most profit oriented and least environmentally aware group. In addition, this group farms more intensely stocked enterprises than the remaining groups. The paper concludes with a discussion of some policy recommendations aimed at increasing the size of the organic sector.
\end{abstract}

Key words: organic farming, former organic farmers, attitudes

\section{Introduction}

Organic production contributes to food safety and environmental protection, as it prohibits production with synthetic inputs, such as manufactured pesticides, artificial fertilizers and genetically modified organisms. For many farmers these attributes are an important motivation for conversion ${ }^{1}$. In addition, availability of subsidy payments and price premiums for organic produce provide economic motivation for conversion. However, there are also a number of barriers in switching to organic farming. For example, organic farming is an information intensive farming method that requires significant learning and changes in the farming system ${ }^{1}$. In addition, there are a number of risks associated with the uptake of organic agriculture, such as market and production risks ${ }^{2}$. Hence, the conversion to organic farming is a challenging process that depends on a variety of factors encompassing economic and non-economic determinants. Diverse motivations for conversion to organic farming, yet high learning costs and risks associated with organic farming, suggest that farmers with certain characteristics may be more likely to convert. However, not all conversion decisions result in long-term organic production as suggested by an over 7\% rate of ceased organic producers in the European Union (EU) in $2005^{3}$. Despite large fluctuations in the organic sector with many farmers adopting and abandoning organic production each year, the organic sector in the EU has increased over the past 10 years, mainly due to policy support and market demand for organic products ${ }^{4}$. Given the commitment of many European governments to increase the size of their organic sectors and considering the large withdrawal rate from organic agriculture, it seems important to implement measures to prevent organic farmers from ceasing production rather than focusing on recruiting new farmers ${ }^{5}$. However, in order to decrease the number of farmers abandoning organic farming, more information about organic, former organic and conventional farmers is required. This study addresses this issue by answering the 
following research questions: what are the characteristics of farmers who successfully adopt organic farming and, more importantly, do these farmers differ from farmers who subsequently ceased organic production and from farmers who do not adopt at all?

The comparison of organic and conventional farmers has attracted considerable attention in the literature. Consequently, several studies have examined the characteristics and attitudes of organic farmers ${ }^{6-11}$. Organic farmers generally differ in their household and farm characteristics from their conventional counterparts: organic farmers are younger, better educated, more likely to be women and from an urban background ${ }^{7}$. Organic farms are often smaller in size with a lower stocking density, although there is a recent trend of larger farms converting to organic farming ${ }^{6,7}$. In terms of personal characteristics and attitudes, organic farmers express a higher level of environmental awareness ${ }^{9,11,12}$, are less motivated by economic reasons ${ }^{1,6}$ and are generally less risk averse than their conventional counterparts ${ }^{13}$. Furthermore, organic farmers prefer different information sources than conventional farmers ${ }^{14}$. For example, it has been argued that organic farmers find that conventional extension services are not particularly helpful ${ }^{6}$.

In contrast, little is known about farmers who subsequently abandoned organic farming and how these farmers differ from organic and conventional farmers. Although, there is a general paucity of studies focusing on former organic farmers, few studies have investigated the reasons for withdrawal. For example, economic reasons such as market access and cost issues, agronomic problems, personal circumstances and regulations such as certifications and inspections were identified to be the main reasons for subsequently abandoning organic production $^{3,4,6}$. In addition, farmers who entered with an economic perspective were found to be more likely to cease organic production at a later stage ${ }^{6}$. Nevertheless, information about farm and personal characteristics of these farmers is largely absent from the literature.

In fact, to date no earlier studies have compared the attitudes and characteristics of organic, former organic and conventional farmers. The present study aims to fill this gap by comparing farm and household characteristics as well as attitudes between organic farmers, farmers who subsequently left organic farming (termed ex-organic farmers thereafter) and conventional farmers. This information has the potential to improve government intervention to promote the adoption of organic agriculture among conventional farmers, while simultaneously reducing the number of subsequent withdrawals from organic production.

\section{The Irish Organic Sector}

Against the backdrop of an ailing macro economy, the Irish government published an ambitious plan for the agricultural sector in July $2010^{15}$. The plan is aimed at increasing the value of the agricultural sector's output, with a view to the Irish agriculture and food industries playing a key role in the overall recovery of the Irish economy. The report sets a target for increasing the value of primary agricultural output by $33 \%$ by 2020 , relative to the average position in the 2007-2009 period. The sector level goal is supported by a number of detailed targets for the key agricultural sub-sectors. In terms of organic farming, the report sets a target to increase the organic farming sector to $5 \%$ of the agricultural land.

Currently, the Irish organic sector is small, occupying just over $1 \%$ of the agricultural area. In comparison, $4.7 \%$ of the agricultural area in the EU is under organic farming ${ }^{16}$. However, recent figures indicate that the Irish organic sector is a growth sector. For example, over the years 2006-2010 there has been a consistent increase of $8 \%$ per annum in organic farm numbers and there were 1386 Irish organic farms in 2010 [DAFM (Department of Agriculture, Food and the Marine), pers. comm., 2010]. Despite an overall growth rate of the sector, many farmers ceased organic production. For example, more than 200 farmers left organic farming between 2003 and 2006. Organic farmers in Ireland are most likely to leave organic farming after a 5 -year-period ${ }^{17}$. This is due to the fact that organic subsidy payments are based on a 5-year contract and leaving the scheme early results in the requirement to pay back the subsidies received.

The Irish government has supported organic farming since June 1994 with the introduction of the Rural Environment Production Scheme in response to regulation (EEC) 2078/92. In addition to the availability of supply side subsidy payments, which are among the highest for EU Member States, demand side market opportunities exist for Irish organic red meat, in particular, export opportunities to the UK and Germany ${ }^{15}$. However, in line with the economic downturn, domestic sales of organic food have decreased over the past few years. Although the decline of organic food sales has been more severe with a decline in value of $16 \%$ between 2009 and 2010, the decline of organic food sales has leveled off to a $1 \%$ decline in value between 2010 and $2011^{18}$. However, according to industry experts, organic farming can still be an economically attractive option for producers ${ }^{18}$.

The small scale of the Irish organic sector is somewhat surprising, given that the typical conventional systems of beef and sheep production in Ireland are generally extensive and mainly grass-based ${ }^{17}$. Therefore, many beef and sheep farmers could easily switch to organic production with relatively little entry cost and alterations in farm management or agronomic practices ${ }^{19}$. Hence, it is not surprising that the majority of organic farmers $(80 \%)$ in Ireland are engaged in cattle and/or sheep farming. In contrast, the Irish organic dairy sector is very small, at about 20 dairy farms. The generally good return from dairying reduces the incentive for farmers to convert 
Table 1. Definition of variables.

\begin{tabular}{|c|c|}
\hline Variable name & Variable description \\
\hline Farm size & $\begin{array}{l}\text { Utilizable agricultural area of the farm } \\
\text { measured in hectares }\end{array}$ \\
\hline LU/ha & Livestock units per hectare \\
\hline Off-farm job & $\begin{array}{l}\text { If the farm operator has an off-farm } \\
\text { job }=1 \text {, otherwise }=0\end{array}$ \\
\hline Age & Age of the farmer in years \\
\hline Gender & $\begin{array}{l}\text { Gender of the farm operator, } \\
\text { women }=1 \text {, otherwise }=0\end{array}$ \\
\hline Higher education & $\begin{array}{l}\text { If the farmer has higher education } \\
\text { (second level or higher) }=1, \\
\text { otherwise }=0\end{array}$ \\
\hline Info advisory & $\begin{array}{l}\text { Frequency of consultation with a farm } \\
\text { advisor, attendance at information } \\
\text { events and agricultural training } \\
\text { courses, divided by three }\end{array}$ \\
\hline Info media & $\begin{array}{l}\text { Frequency of using magazines/press, } \\
\text { TV/radio and the Internet as a } \\
\text { source of farming information, } \\
\text { divided by three }\end{array}$ \\
\hline $\begin{array}{l}\text { Knows another } \\
\text { organic farmer }\end{array}$ & $\begin{array}{l}\text { If the farmer knows another organic } \\
\text { farmer }=1 \text {, otherwise }=0\end{array}$ \\
\hline $\begin{array}{l}\text { Environmental } \\
\text { attitude }\end{array}$ & $\begin{array}{l}\text { Higher value }=\text { higher level of } \\
\text { environmental concern }\end{array}$ \\
\hline Profit orientation & $\begin{array}{l}\text { Higher value }=\text { higher profit } \\
\text { orientation }\end{array}$ \\
\hline Risk attitude & Higher value $=$ more risk averse \\
\hline $\begin{array}{l}\text { Information gathering } \\
\text { attitude }\end{array}$ & $\begin{array}{l}\text { Higher value }=\text { higher interest in } \\
\text { information gathering }\end{array}$ \\
\hline
\end{tabular}

and, although Irish dairy farming is mainly grass based, dairy farms are managed in a more intensive way than drystock farms, thus making conversion more difficult. More importantly, there is only one main organic processor handling most of the organic milk, which implies that there are fundamental logistical difficulties in milk collection and processing. The second biggest organic sector is the horticultural sector, with about 300 growers. However, of these farms, there are only about 20 main growers that manage more than 6ha [DAFM (Department of Agriculture, Food and the Marine), pers. comm., 2010]. This study focuses on drystock farmers, since the majority of organic farms can be found in this category. In addition, it is assumed that the decision of dairy and horticultural farmers to enter or exit the organic sector is different from the decision of drystock farmers, mainly due to different market conditions.

\section{Methodology}

\section{Survey design and hypotheses}

A questionnaire was developed which aimed at gathering information on farmers' attitudes and characteristics. The questionnaire consisted of several sections: (1) farm characteristics; (2) household characteristics; (3) frequency of information use; and (4) attitude statements regarding the environment, risk, profit motivation and information gathering.

All included attitude scales were measured by means of a number of statements, since attitude scales derived from a series of statements are regarded as superior to attitude scales derived from single questions ${ }^{20,21}$. The respondents were asked to agree or disagree with each statement on a 7-point scale ranging from -3 (= disagree very strongly) to +3 (= agree very strongly). In total, 35 statements were included in the survey. Some of the statements were adopted from the literature, but adjusted to Irish farming conditions. In order to avoid the respondents automatically choosing the same answer to consecutive statements and to keep their attention, statements for the same attitude scale were randomly scattered within all statements. In addition, positive- and negative-phrased statements were used, which means that seemingly contradictory statements were employed to assess farmers' attitudes as accurately as possible. In order to get the same meaning for all labels, negative statements were then recoded for statistical analysis. Finally, prior to conduction of the quantitative survey, the questionnaire was piloted with 20 farmers and the wording was adjusted based on the feedback received.

Table 1 provides an overview and description of the variables assessed in the survey. In terms of frequency of information use, the variables, info advisory and info media serve as a proxy to capture information use of the farmer. Info advisory measures the frequency of consulting a farm advisor, attending an information event or agricultural training course in the past 12 months divided by three. Info media measures how frequently the farmers used magazines/press, TV/radio or the Internet as a source for farming information in the past 12 months, also divided by three. Guided by the literature, statements in relation to the following attitudes are included: environmental attitude, profit orientation, risk attitude as well as attitudes toward information gathering $8,9,11,22$.

Overall, the survey is designed to address the aforementioned research questions: what are the characteristics of farmers who successfully adopt organic farming, and more importantly, do these farmers differ from farmers who subsequently ceased organic production and from farmers who do not adopt at all? More specifically, given the different choices made by farmers, significant differences in the farm and household characteristics (Hypothesis 1) as well as attitudes (Hypothesis 2) between conventional, organic and ex-organic farmers are expected. In addition, more precise hypotheses are tested in relation to specific attitude scales. For example, it is hypothesized that farmers who express a high level of environmental awareness are more likely to adopt and stay in organic farming. Therefore, it is expected that organic farmers state a higher level of environmental awareness than conventional and ex-organic farmers 
(Hypothesis 3). Given the finding that organic farming is often a lifestyle choice ${ }^{1}$, it is hypothesized that organic farmers are less profit oriented than ex-organic and conventional farmers. In particular, ex-organic farmers are expected to be more profit motivated than organic farmers, as their adoption decisions have previously been found to be more economic driven ${ }^{6}$ (Hypothesis 4). The adoption of organic farming entails a number of risks ${ }^{13}$, therefore it is hypothesized that organic farmers are less risk averse than conventional farmers, but ex-organic farmers are expected to be the least risk averse group as they are willing to try new farming methods (Hypothesis 5). Finally, due to the importance of information on technology adoption in general and the fact that organic farming is an information intensive farming technique in particular $^{1}$, it is expected that organic farmers express a higher level of information gathering attitude than conventional and ex-organic farmers (Hypothesis 6). For example, more information on the technical aspects and marketing of organic produce could contribute to fewer exits from organic farming ${ }^{6}$, as more information gathering may lead to better informed decisions.

\section{Data}

Data collection was administered as follows: complete address lists as of January 2008 were available for organic and ex-organic farmers from the Irish organic certification bodies (Irish Organic Farmers and Growers Organization and Organic Trust Ltd). A questionnaire was sent to each farmer on the list. Following an announcement of the survey in the Irish Farmers' Journal newspaper and one reminder letter, a response rate of $40 \%$ from the organic and $22 \%$ from the ex-organic farmers was achieved. A farmer was classified as organic if the farm was registered as organic or in conversion with the Irish Department of Agriculture, Food and the Marine in 2008, whereas a farmer was classified as ex-organic if the farm was registered as organic or in conversion at some point in the past.

Data for the conventional farmers were collected through Irish National Farm Survey (NFS) farms ${ }^{23}$. For this analysis, a subsample of the NFS farms was used and the majority of data were received from a supplementary survey (i.e., the previously described survey). In general, the NFS was established in 1972 and has been conducted on an annual basis since then. The NFS is collected as part of the EU-Farm Accountancy Data Network (FADN), providing a representative sample of Irish farms. Overall, there are approximately 1100 in the survey each year, representing a farming population of 110,000 farms.

After restriction of the analysis to drystock farms (i.e., farms with cattle and/or sheep), the final sample consisted of 596 farmers with the following breakdown: 341 organic, 50 ex-organic and 164 conventional farmers. This study focuses on drystock farms, since significant numbers of organic farms, necessary for a quantitative analysis, can be found in this sector.

\section{Statistical analyses}

Principal component analysis (PCA) with orthogonal (varimax) rotation was employed to the attitude statements as it reveals the underlying structure of the data and reduces dimensionality. That is, PCA was applied to empirically confirm whether each statement has the anticipated meaning, i.e., loads on the respective component. Statements were retained if they had loadings near or above 0.6 on one component and 0.2 or less on all other components ${ }^{22}$. This procedure reduced the number of statements to 23 , as the remaining statements showed loadings on more than one component and are thus not pure measures of any one attitude scale. The final PCA confirmed the hypothesized four attitude scales, when retaining principal components with eigenvalues greater than on $\mathrm{e}^{24}$. The four principal components explained $54.5 \%$ of the variance of the statements. This exceeds the minimum adequacy measure, as in some cases $50 \%$ of the explained variance can serve as a sufficient summary ${ }^{25}$. Each attitude scale was then computed as the mean of the original scores of the respective statements. Internal consistency of the attitude scales was measured with Cronbach's $\alpha$.

Next, the sample was divided into the three previously defined farmers' groups (i.e., organic, ex-organic and conventional farmers). Differences between the three groups were assessed using analysis of variance for continuous variables and Chi-square statistics for comparisons of frequencies of categorical variables. Direct comparison between any two groups was conducted with $t$ tests for continuous variables or Chi-square statistics for categorical variables.

\section{Results and Discussion Comparison of farm and household
characteristics}

The farm and household characteristics of the three groups are shown in Table 2. The mean values are reported along with the results of statistical tests of significant differences between the three groups. Statistical test results of differences between any two groups are included in the text. Overall, the three groups differ significantly with respect to the reported farm and household characteristics.

Conventional farmers have larger $(t=-7.21 ; P=0.00)$ and more intensely stocked $(t=-6.89 ; P=0.00)$ farms than their organic and ex-organic counterparts. Initially, organic agriculture was more likely to be adopted by smaller and more extensively farmed enterprises ${ }^{7}$, but there has been a recent shift to larger and more commercially oriented farms converting to organic 
Table 2. Farm and household characteristics of farmer groups.

\begin{tabular}{|c|c|c|c|c|}
\hline Characteristic & $\begin{array}{c}\text { Organic farmers } \\
\quad n=381\end{array}$ & $\begin{array}{c}\text { Ex-organic farmers } \\
\qquad n=\mathbf{5 0}\end{array}$ & $\begin{array}{c}\text { Conventional farmers } \\
\qquad n=164\end{array}$ & Difference \\
\hline Farm size & $35.47(23.56)$ & $29.45(38.49)$ & $45.79(39.90)$ & $*$ \\
\hline LU/ha & $0.82(0.44)$ & $0.54(0.45)$ & $1.08(0.49)$ & $*$ \\
\hline Off-farm job & $0.44(0.50)$ & $0.66(0.48)$ & $0.33(0.47)$ & * \\
\hline Age & $49.65(10.63)$ & $55.16(9.78)$ & $53.73(11.32)$ & $*$ \\
\hline Gender & $0.15(0.35)$ & $12.0(0.33)$ & $0.04(0.20)$ & $*$ \\
\hline Higher education & $0.73(0.44)$ & $0.72(0.45)$ & $0.65(0.48)$ & $* *$ \\
\hline Info advisory & $0.99(0.77)$ & $0.65(0.74)$ & $0.69(0.72)$ & $*$ \\
\hline Info media & $3.56(1.64)$ & $2.85(2.12)$ & $3.46(1.33)$ & $* *$ \\
\hline Knows another organic farmer & $0.87(0.34)$ & $0.82(0.40)$ & $0.35(0.48)$ & $*$ \\
\hline
\end{tabular}

Mean and standard deviation in parentheses, the column labeled. Difference indicates whether a significant difference exists in the means of variables of the three farmer groups based on an $F$-test or a $\chi^{2}$ test. A $\chi^{2}$ test was used on the following variables: off-farm job, age, gender, higher education and knows another organic farmer.

$* * *$ indicates significance at the 99 and $95 \%$ level, respectively.

methods ${ }^{6,9}$; a trend that cannot be confirmed in this study. There is no significant difference in terms of farm size between organic and ex-organic farms $(t=1.08 ; P=0.27)$, while organic farms have a higher stocking density than ex-organic farms $(t=4.13 ; P=0.00)$.

Organic farmers are more likely to be engaged in offfarm work than conventional farmers $\left(\chi^{2}=6.45 ; P=0.01\right)$, which could be due to the fact that organic farms are smaller than conventional farms. However, this is in contrast to the general finding that organic farming is more labor intensive ${ }^{26}$, which interferes with engaging in off-farm work. It is also worth noting that the ex-organic farmers are the group with the highest proportion of farmers having an off-farm job $\left(\chi^{2}=11.83 ; P=0.00\right)$. Generally, farmers involved in off-farm work have less time to spend on farming activities, which can initially complicate the ease of adjustment to organic methods. In addition, these farmers face higher opportunity costs of labor, which are especially important if the new method requires higher labor input ${ }^{27}$.

In line with the previous findings ${ }^{6,7}$, organic farmers are younger than ex-organic $(t=-3.71 ; P=0.00)$ and conventional farmers $(t=-3.94 ; P=0.00)$, while a higher proportion of organic and ex-organic than conventional farmers are women $\left(\chi^{2}=12.04 ; P=0.00\right)$. In addition, organic and ex-organic farmers are also found to be somewhat better educated than conventional farmers $\left(\chi^{2}=3.92 ; P=0.05\right)$, while no significant difference is evident between organic and ex-organic farmers.

In terms of frequency of information use, there are significant differences evident between the three groups. Organic farmers use advisory services more often than conventional farmers $(t=4.40 ; P=0.00)$, while there is no significant difference between these two groups in terms of use of media information. Similarly, previous studies also argued that organic and conventional farmers use different information sources ${ }^{14}$. Organic farmers also utilize a higher number of information sources than exorganic farmers, both in terms of information from advisory services $(t=3.06 ; P=0.00)$ and information from the media $(t=2.75 ; P=0.01)$. In this context, Rigby et al. ${ }^{6}$ reported that some organic farmers in the UK had little experience and knowledge when converting to organic farming, which subsequently led to a withdrawal from organic production due to failure to make a living.

Whether or not the farmer knows another organic farmer is used as a proxy for social learning. As expected, organic and ex-organic farmers are more likely to know another organic farmer than conventional farmers $\left(\chi^{2}=162.58 ; P=0.00\right)$. Other organic farmers are seen as an important source of information for farmers involved in converting to organic farming ${ }^{11}$. Furthermore, adopters are usually closely related through information networks, and high social integration can enhance adoption $^{28}$.

\section{Results of principal component analysis}

PCA confirmed the anticipated four attitude scales, which are then employed for further analysis. The statements related to each attitude scale are shown in Table 3 and described below. All attitude scales exhibit a Cronbach's $\alpha$ of close to or above 0.7 .

Environmental attitude: this attitude scale comprises ten statements, which are related to environmental protection in agriculture and to organic farming in particular. A farmer who expresses a positive attitude toward the environment, i.e., is environmentally aware, generally agrees with statements such as 'It is important to be sensitive to the environmental impacts of farming by reducing input use on the farm.' Cronbach's $\alpha$ of this attitude scale is 0.87 .

Profit orientation: this attitude scale consists of five statements, which measure profit orientation in farming methods, as well as in a wider context of the adoption of new technologies. A farmer who has a high score in statements such as 'It is important to make the largest possible profit from farming' or 'It is important to try new 
Table 3. Attitude statements.

Environmental attitude

It is important to be sensitive to the environmental impacts of farming by reducing input use on the farm

The use of chemical inputs has a negative impact on the health of people and animals

It is important to take the environment into consideration, even if it lowers profit

It is important to farm in an environmentally friendly way

The impact of fertilizer run-off is worse than generally imagined

Organic farming is better for the environment than conventional farming

The use of chemicals in agriculture makes sense as long as it leads to an increase in profits (-)

Maximizing profits is more important than protecting the environment (-)

Organic farming is a fad (-)

Chemical fertilizers have no harmful effects; they promote high-quality production (-)

Profit orientation

It is important to receive the highest possible prices for the produce

It is important to make the largest possible profit from farming

It is important to try new ways to increase profit

Farming is about maximizing profits from farm business

To survive in farming, a farmer has to adapt to changing and new technologies

Risk attitude

Before applying different farming practices they first need to be proven on other farms

It is important to be cautious about adopting new ideas

It is important to avoid risky options in farm decision-making

Before adopting new ways of doing things it is important to see them working for other people

Information seeking attitude

It is important to discuss farming options with other farmers/friends

It is important to read about farming practices

It is important to have good contact with other farmers to discuss farm-related issues

It is important to visit other farms to look at their farming methods

All statements were measured from -3 to +3 ; re-coded statements are indicated by $(-)$.

ways to increase profit' is considered to be profit oriented with regard to the farm enterprise. Cronbach's $\alpha$ of this attitude scale is 0.76 .

Risk attitude: this attitude scale is measured by four statements, which relate to risk-taking behavior in farming. All of the statements are closely linked to the risk a farmer is willing to take when making farming decisions. A farmer who scores high in statements such as 'It is important to avoid risky options in farm decision-making' is regarded as risk averse. Cronbach's $\alpha$ of this attitude measurement is 0.69 .

Information seeking attitude: this attitude scale consists of four statements. A farmer who scores high in this attitude scale agrees with statements such as the following: 'It is important to visit other farms to look at their farming methods' or 'It is important to read about farming practices.' Cronbach's $\alpha$ of this attitude scale is 0.79 .

\section{Comparison of attitudes}

The scores of the attitude scales are reported in Table 4 along with the results of the statistical tests of difference between the three groups. Statistical test results of differences between any two groups are included in the text.

The three farmer groups differ significantly with regard to environmental attitude. Organic farmers express a higher level of environmental awareness than ex-organic $(t=1.87 ; P=0.06)$ and conventional farmers $(t=20.72$; $P=0.00$ ). The latter result is in line with previous findings that organic farmers generally have a more positive attitude toward the environment than conventional farmers $^{8,12}$. The finding that ex-organic farmers have a lower level of environmental awareness than organic farmers may be an indicator that this group was less committed to organic principles, a problem previously mentioned by Flaten et al. ${ }^{9}$. However, ex-organic farmers have a higher level of environmental awareness than conventional farmers $(t=-8.79 ; P=0.00)$, suggesting that even when a positive attitude toward the environment exists, this does not guarantee long-term conversion. For example, profit motives may be stronger than environmental motives, even when the farmer states an awareness of environmental problems ${ }^{29}$.

The three groups also differ significantly in terms of their attitudes toward profit. Conventional farmers express a higher profit orientation than their organic $(t=-4.05 ; \quad P=0.00)$ and ex-organic counterparts $(t=-4.57 ; P=0.00)$, while there is no difference in the level of profit orientation between organic and ex-organic farmers $(t=1.41 ; P=0.16)$. Organic farmers were thought to be less profit oriented than conventional farmers, but there is evidence in the literature that organic farmers' 
Table 4. Attitude scales grouped by organic, ex-organic and conventional farmers.

\begin{tabular}{|c|c|c|c|c|}
\hline Attitude & $\begin{array}{c}\text { Organic farmers } \\
n=381\end{array}$ & $\begin{array}{c}\text { Ex-organic farmers } \\
n=\mathbf{5 0}\end{array}$ & $\begin{array}{c}\text { Conventional farmers } \\
n=164\end{array}$ & Difference \\
\hline Environmental attitude & $2.19(0.72)$ & $1.98(0.88)$ & $0.66(0.95)$ & $*$ \\
\hline Profit orientation & $1.58(1.09)$ & $1.36(1.06)$ & $1.96(0.73)$ & $*$ \\
\hline Risk attitude & $1.22(1.08)$ & $0.91(0.98)$ & $1.45(0.86)$ & $*$ \\
\hline Information seeking attitude & $2.02(0.85)$ & $1.81(0.97)$ & $1.62(0.89)$ & $*$ \\
\hline
\end{tabular}

Mean and standard deviation in parentheses, the column labeled difference indicates whether a significant difference exists in the means of variables of the three farmer groups based on an $F$-test.

* Indicates significance at the $99 \%$ level. Scales range from -3 (disagree very strongly) to +3 (agree very strongly).

conversion decisions became increasingly motivated by economic reasons ${ }^{1,9}$. Furthermore, farmers who subsequently withdrew from organic production have also been found to be more economically oriented ${ }^{6}$, a finding that cannot be confirmed in this study.

There are also significant differences between the three groups with regard to risk attitudes. Organic and exorganic farmers are less risk averse than conventional farmers $(t=-2.85 ; P=0.00)$, which is in line with previous findings by Flaten et al. ${ }^{13}$. Organic producers are exposed to numerous sources of risks; for example, due to reduction in yields, restrictions in the use of pesticides and chemical fertilizers or locating new market outlets for organic produce, which provides an explanation that organic farmers are less risk averse. Comparing organic to ex-organic farmers, ex-organic farmers were found to be less risk averse $(t=2.08 ; P=0.04)$. Depending on the risk attitude of a farmer, similarly perceived risks may have a different impact on adoption behavior $^{2}$. Hence, a less risk averse farmer will adopt organic practices more easily than a more risk averse farmer, which may be one explanation that ex-organic farmers were found to be the least risk averse group. In addition, conventional farmers, who are found to be the most risk averse group in this study, may perceive the risks associated with organic farming as more severe than more risk neutral farmers, which could impede adoption.

The three groups also differ with regard to their information seeking attitudes. Conventional farmers rate information gathering as less important than the remaining two groups $(t=4.74 ; P=0.00)$. Organic farming is an information intensive farming technique and successful conversion requires knowledge and information acquisition $^{1}$. Gathering information can raise general awareness of organic farming and reduce uncertainty about the outcomes of the new method. The results also indicate that ex-organic farmers rate information gathering as slightly less important than organic farmers $(t=1.68$; $P=0.09$ ), which may be one explanation for subsequent withdrawal from organic farming as previously reported by Rigby et al. $^{6}$ for farmers in the UK. Ex-organic farmers' decisions may have been less informed than organic farmers' decisions, which may have caused problems and subsequent withdrawal.

\section{Conclusions and Policy Implications}

Despite an overall growth rate of the organic farming sector, a considerable number of farmers cease organic production each year. Nevertheless, little is known about farmers who adopt and subsequently abandon organic farming. By explicitly considering former organic farmers, the present paper addresses this gap in the literature. It compares and contrasts farm and household characteristics as well as attitudes of organic, former organic and conventional farmers.

Overall, the results of this study confirm significant differences between the three groups. More specifically, the three groups differ with regard to their farm and household characteristics (Hypothesis 1). Organic farmers are younger and utilize more information sources than the remaining groups. They have less intensely stocked farms than conventional farmers, while ex-organic farmers manage the least intensely stocked farms and have the highest proportion of farmers with an off-farm job. Conventional farmers manage the largest and most intensely farmed enterprises, are less likely to be women and to know another organic farmer.

The results also confirmed Hypothesis 2, as the three groups differ with regard to their attitudes. More specifically, organic farmers are found to express the highest level of environmental awareness, while conventional farmers are the least environmentally aware group (Hypothesis 3). Conventional farmers are more profit oriented than organic and ex-organic farmers, but the hypothesis that ex-organic farmers are more profit oriented than organic farmers cannot be confirmed (Hypothesis 4). Ex-organic farmers stand out as being the least risk averse group, while conventional farmers are the most risk averse group, thus confirming Hypothesis 5. Finally, conventional farmers rank information gathering as less important than the other two groups, while organic farmers express a higher level of information gathering attitude than ex-organic farmers (Hypothesis 6).

The results of this study have important policy relevance in terms of promoting an increase in organic conversion of agricultural producers. Environmental awareness of the farmer emerged to be an important 
characteristic for long-term conversion. Thus, increasing farmers' environmental awareness could help to increase conversion to organic farming. However, environmental awareness itself is not enough to secure conversion, as indicated by the stated positive environmental awareness of farmers who left organic farming. It is likely that farmers who cease organic production encounter problems, which may be due to economic or technical reasons. In this context, information provision is a key factor for increasing the uptake of organic farming. However, this study has shown that conventional farmers rank information gathering as less important, thus effective means to disseminate information need to be identified to reach those farmers. It appears that conventional farmers mainly rely on the media and the Internet to receive information, which could be a potential channel to disseminate information on organic farming. Information provision is also important as a means to reduce risk. This is important as conventional farmers were found to be the most risk averse group, thus less willing to take risks in their farming decisions. However, advice and information about organic farming must clearly spell out the downside as well as the benefits. For example, it may be the case that in the absence of adequate information gathering many farmers converted abruptly, which ended in withdrawal from organic production for some. Therefore, it should also be the aim of the policymakers to reduce the number of farmers who subsequently drop out of organic farming, which may be easier than recruiting new farmers to organic farming. Consequently, it is paramount that information provision and advice are not only targeted toward potential entrants but also support existing organic farmers, especially in the first years of organic farming.

Acknowledgements. The author thanks the Teagasc National Farm Survey Department for data collection and acknowledges Teagasc Walsh Fellowship Scheme and Irish Research Council (IRC) funding for this research.

\section{References}

1 Padel, S. 2001. Conversion to organic farming: a typical example of the diffusion of an innovation? Sociologia Ruralis 41:40-62.

2 Gardebroek, C. 2006. Comparing risk attitudes of organic and non-organic farmers with a Bayesian random coefficient model. European Review of Agricultural Economics $33: 485-510$.

3 LLorens Abando, L. and Rohner-Thielen, E. 2007. Different Organic Farming Patterns within EU-25: An Overview of the Current Situation; Statistics in Focus, Eurostat. Available at Web site http://epp.eurostat.ec.europa.eu/cache/ITY OFFPUB/KS-SF-07-069-EN.PDF (accessed April 2012).

4 Sahm, H., Sanders, J., Nieberg, H., Behrens, G., Kuhnert, H., Strom, R., and Hamm, U. 2012. Reversion of organic to conventional agriculture: a review. Renewable Agriculture and Food Systems. Available on Cambridge Journals Online 2012 doi:10.1017/S1742170512000117.

5 Flaten, O., Lien, G., Koesling, M., and Loes, A.K. 2010. Norwegian farmers ceasing organic production: characteristics and reasons. Journal of Environmental Management 91:2717-2726.

6 Rigby, D., Young, T., and Burton, M. 2001. The development of and prospects for organic farming in the UK. Food Policy 26:599-613.

7 Padel, S. and Lampkin, N.H. 1994. Farm level performance of organic farming systems: an overview. In N.H. Lampkin and S. Padel (eds). The Economics of Organic Farming: an International Perspective. CAB International, Oxford, UK, p. 201-219.

8 McCann, E., Sullivan, S., Erickson, D., and DeYoung, R. 1997. Environmental awareness, economic orientation, and farming practices: a comparison of organic and conventional farmers. Environmental Management 21:747758.

9 Flaten, O., Lien, G., Ebbesvik, M., Koesling, M., and Valle, P. 2006. Do the new organic producers differ from the 'old guard'? Empirical results from Norwegian dairy farming. Renewable Agriculture and Food Systems 21:174 182.

10 Lockeretz, W. 1995. Organic farming in Massachusetts: an alternative approach to agriculture in an urbanised state. Journal of Soil and Water Conservation 50:663-667.

11 Egri, C. 1999. Attitudes, backgrounds and information preferences of Canadian organic and conventional farmers: implications for organic farming advocacy and extension. Journal of Sustainable Agriculture 13:45-72.

12 Burton, M., Rigby, D., and Young, T. 2003. Modelling the adoption of organic horticultural technology in the UK using duration analysis. Australian Journal of Agricultural and Resource Economics 47:29-54.

13 Flaten, O., Lien, G., Koesling, M., Valle, P.S., and Ebbesvik, M. 2005. Comparing risk perceptions and risk management in organic and conventional dairy farming: empirical results from Norway. Livestock Production Science 95:1125.

14 Burton, M., Rigby, D., and Young, T. 1999. Modelling the adoption of organic horticultural techniques in the UK. Journal of Agricultural Economics 50:47-63.

15 DAFM (Department of Agriculture, Food and the Marine) 2010. The Food Harvest 2020: a vision for Irish agri-food and fisheries. Department of Agriculture, Food and the Marine, Dublin, Ireland.

16 Willer, H. and Kilcher, L. 2011. The World of Organic Agriculture: Statistics and Emerging Trends 2011. 12th ed. IFOAM, Bonn; FiBL, Frick; ITC, Geneva.

17 Läpple, D. 2010. Adoption and abandonment of organic farming: an empirical investigation of the Irish drystock sector. Journal of Agricultural Economics 61:697714.

18 Bourke, L. 2011. Market potential for organic food and Irish consumer expectations. Presentation at the Teagasc National Organic Conference, Ireland.

19 Reidy, J. 2006. Organic cattle/sheep production. Fact Sheet No. 32, Teagasc, Ireland.

20 Osgood, A.N. 1992. Questionnaire Design and Attitude Measurement. Basic Books Inc., New York. 
21 Fishbein, M. and Ajzen, I. 1975. Belief, Attitude, Intention and Behavior: An Introduction to Theory and Research. Addison-Wesley, Reading, MA, USA.

22 Willock, J., Deary, I.J., McGregor, M.J., Sutherland, A., Edwards-Jones, G.J., Morgan, O., Dent, B.J., Grieve, R., Gibson, G., and Austin, E. (1999). Farmers' attitudes, objectives, behaviours, and personality traits: the Edinburgh study of decision making on farms. Journal of Vocational Behaviour 54:5-36.

23 Connolly, L., Kinsella, A., Quinlan, G., and Moran, B. 2009. National Farm Survey Teagasc. Rural Economy Research Centre, Athenry, Ireland.

24 Lewis-Beck, M. 1994. Factor Analysis and Related Techniques. Vol. 5, International Handbooks of Quantitative Applications in the Social Sciences. SAGE Publications, London, UK.

25 Everitt, B. and Dunn, G. 1991. Applied Multivariate Data Analysis. Halsted Press, London, UK.
26 Offermann, F. and Nieberg, H. 2000. Economic Performance of Organic Farms in Europe; Organic Farming in Europe: Economics and Policy, Vol. 5. University of Hohenheim, Stuttgart, Germany.

27 Moser, C. and Barrett, C. 2003. The disappointing adoption dynamics of a yield-increasing, low external-input technology: the case of SRI in Madagascar. Agricultural Systems 76:1085-1100.

28 DeSouza Filho, H., Young, T., and Burton, M. 1999. Factors influencing the adoption of sustainable agricultural technologies, evidence from the state of Espirito Santo, Brazil. Technological Forecasting and Social Change 60:97112.

29 Lynne, G. and Rola, L. 1988. Improving attitude-behaviour prediction models with economic variables: farmer actions toward soil conservation. Journal of Social Psychology 128:19-28. 